\title{
Keanekaragaman Spesies Kupu-Kupu (Lepidoptera) pada Habitat Eko-wisata Taman Bunga Merangin Garden Bangko Jambi
}

\author{
Bayu Kurniawan ${ }^{*}$, Rila Rahma Apriani ${ }^{2}$, Srianika Cahayu ${ }^{3}$ \\ 13 Tadris Biologi, Fakultas Tarbiyah dan Keguruan, UIN STS Jambi \\ 2 Agroekoteknologi, Fakultas Pertanian, ULM \\ E-mail : bayu.kurniawan@uinjambi.ac.id
}

\begin{abstract}
Butterflies play an important role in the balance of ecosystems and function as a bioindicator for clean/healthy environment. Degradation and fragmentation of natural habitats threat the population of butterflies. Habitat conservation through eco-tourism is an way to keep the existance butterfly species. This study aims to identify the butterflies species, analyze species diversity, and abundance of butterflies (Lepidoptera) in the eco-tourism habitat of Merangin Garden Bangkang Jambi flower garden. Sampling was carried out five times at December 2018 to March 2019 using insect net. A total of 3 families from 16 species found. The species that dominated was Junonia orithya with 88 individuals (16.4\%). The biodiversity value of butterflies species was 2.68. Diversity index is the lowest level of diversity. The types of flowers that bloom affect the high or low diversity index values. The most of butterflies found at $7.30-9.30$ AM.

Keyword: butterflies, diversity, eco-tourism, Jambi, Merangin garden
\end{abstract}

\begin{abstract}
Abstrak
Kupu-kupu berperan penting dalam keseimbangan ekosistem dan berfungsi sebagai bioindikator ekologis yang baik pada lingkungan hidup. Degradasi dan fragmentasi habitat alami menjadikan ancaman terhadap keberlangsungan hidup kupu-kupu. Konservasi habitat melalui eko-wisata salah satu upaya menjaga kelestarian spesies kupu-kupu. Penelitian ini bertujuan untuk mengidentifikasi jenis kupu-kupu, menganalisis keanekaragaman jenis, dan kemelimpahan kupu-kupu (Lepidoptera) pada habitat eko-wisata taman bunga merangin garden Bangko Jambi. Penelitian ini dilakukan sebanyak lima kali dari bulan Desember 2018 hingga Maret 2019 yang dilakukan mulai puku 07.3014.30 WIB. Sebanyak 3 famili dari 16 jenis spesies ditemukan. Spesies yang mendominasi adalah Junonia orithya dengan jumlah individu sebanyak 88 ekor $(16,4 \%)$. Keanekaragaman kupu-kupu tertinggi 2,68 ditemukan pada penelitian ke III dengan nilai dominansi 0,08 dan keanekaragaman terendah 2,40 pada penelitian ke IV dengan nilai dominansi 0,11. Indeks keanekaragaman tergelong tingkat keanekaragaman sedang. Jenis bunga yang mekar mempengaruhi tinggi rendahnya nilai indeks keanekaragaman. Kunjungan kupu-kupu ke bunga tertinggi terjadi pada pukul 07.30 - 09.30 WIB.
\end{abstract}

Kata Kunci: Eko-wisata, Keanekaragaman, Kupu-kupu, Merangin Garden

\section{Pendahuluan}

Indonesia merupakan salah satu negara yang memiliki biodiversitas tertinggi di dunia. Indonesia menempati posisi kedua setelah Brazil, sehingga dikenal dengan sebutan Megabiodiversity (Yanuar at al, 2011). Salah satu keanekaragaman hayati tertinggi di Indonesia adalah kupu-kupu. Kupu-kupu yang ditemukan di Indonesia sekitar 2.000-2.500 spesies dari 17.500 spesies yang dikenal di seluruh dunia (Leo at al, 2016), beberapa diantaranya termasuk dalam daftar merah (redlist)
International Union for the Conservation of Nature and Natural Resources (IUCN) sebagai jenis yang dilindungi (Fox at al, 2018).

Kupu-kupu merupakan aspek penting yang memilik peran ekologis. Kupu-kupu juga dikenal sebagai indikator ekologis yang baik pada lingkungan hidup (Zhongmin dan Yunfei, 2012 karena sensitif terhadap degradasi habitat dan perubahan iklim (Tiple, 2012). Kupu-kupu juga memiliki peranan sebagai polinator dan turut memberi andil dalam mempertahankan 
keseimbangan ekosistem (Ghazanfar at al, 2016).

Saat ini, kupu-kupu menghadapi ancaman kepunahan yang disebabkan oleh konversi lahan di habitatnya. Keberadaan populasi kupu-kupu pada habitat bergantung pada keanekaragaman inang dan ketersediaan makanan sehingga memberikan korelasi yang positif antara keanekaragaman dengan kondisi habitatnya (Koneri \& Maabuat, 2016). modifikasi habitat menyebabkan terjadinya degradasi, fragmentasi dan hilangnya habitat asli serta berdampak pada penurunan keanekaragaman jenis inang menjadi faktor penyebab penurunan keanekaragaman dan kemelimpahan kupu-kupu (Gandhi \& Kumar, 2015). Konservasi habitat secara buatan untuk mempertahankan jenis inang merupakan salah satu upaya yang terus dilakukan dalam pelestarian kupu-kupu. Salah satunya yaitu dengan dibuatnya Taman Bunga Merangin Garden.

Merangin Garden merupakan salah satu wisata taman bunga terluas di Sumatera dengan luas lahan 6 hektar $\left(60.000 \mathrm{~m}^{2}\right)$, terletak di kabupaten Merangin propinsi Jambi dan terdapat berbagai jenis bunga. Habitat taman bunga merangin garden merupakan perubahan habitat alami menjadi habitat buatan manusia sebagai eko-wisata. Selain sebagai tempat wisata yang memiliki nilai estetika, taman bunga ini juga memiliki fungsi ekologis yang ideal bagi kupu-kupu sebagai keseimbangan layanan ekosistem. Pengelolaan habitat berupaya memaksimalkan satu layanan ekosistem tertentu, yaitu dengan meningkatkan dan memanipulasi sumber daya dilakukan dengan memilih tanaman yang menyediakan sumber daya terbatas seperti serbuk sari, nektar, inang alternatif, atau habitat dalam sistem yang dikelola (Fiedler at al, 2008).

Penelitian ini bertujuan untuk mengidentifikasi jenis kupu-kupu, menganalisis keanekaragaman jenis dan kemelimpahan kupu-kupu (Lepidoptera) pada habitat eko-wisata taman bunga merangin garden Bangko Jambi.

\section{Metode}

Penelitian ini dilakukan mulai 9 Desember 2018 - 9 Maret 2019 di taman bunga Merangin Garden Merangin Jambi dengan titik koordinat $2^{\circ} 02^{\prime} 54.90^{\prime \prime} \mathrm{S} \quad-102^{\circ} 18^{\prime} 03.66^{\prime \prime} \mathrm{E}$ dengan ketinggian $301 \mathrm{mdpl}$ dengan luas area 6 Ha. Koleksi kupu-kupu dilakukan sebanyak 5 (lima) kali dimulai dari tanggal 9-15 Desember
2018 (7 hari) (I), 30 Desember - 5 Januari 2019 (7 hari) (II), 20-26 Januari 2019 (7 hari) (III), 1016 Februari 2019 (7 hari) (IV), 3-9 Maret 2019 (7 hari) (V) di taman bunga Merangin Garden.

Penelitian ini menggunakan metode eksploratif dengan menjelajah lokasi penelitian dilakukan mulai pukul 07.30 hingga pukul 14.30 WIB. Alat yang digunakan pada penelitian ini meliputi insect net, handcounter, kertas papilot, killing bottle dan drying box. Bahan yang digunakan dalam penelitian ini meliputi kloroform 10\%, kapas, dan potongan karet gelang.

Kupu-kupu yang terkoleksi menggunakan insect net dicatat untuk setiap jenisnya yang sudah diketahui dan dihitung kelimpahannya. Kupu-kupu yang terkoleksi dimasukkan kedalam kertas papilot untuk penyimpanan sementara menjaga sayap kupukupu tidak rusak. Kupu-kupu terkoleksi dibuat awetan untuk proses identifikasi dengan metode spreading setting dan dikeringkan menggunakan drying box selama 12 jam (Gullan \& Cranston, 2010). Identifikasi kupu-kupu dilakukan menggunakan buku determinasi dari Peggi \& Amir, (2006) dan Borror et al., (1992).

Data yang didapatkan ditabulasikan kedalam ms.excell untuk dianalisis menggunakan analisis indeks keanekaragaman Shannon Wiener dan indeks Simpson (Brewer, 1994).

\section{Shannon Wiener Index}

$\left(\mathrm{H}^{\prime}\right)=-\Sigma \mathrm{p}_{\mathrm{i}} \log \mathrm{p}_{\mathrm{i}}$

Keterangan :

H': indeks keanekaragaman Shannon-Wienner $\mathrm{p}_{\mathrm{i}}$ : proporsi spesies ke i di dalam sampel total

Simpson

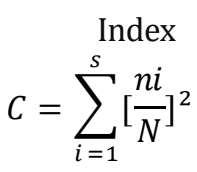

Keterangan :

C : indeks dominansi Simpson

ni : jumlah individu jenis ke-i

$\mathrm{N}$ : jumlah total individu

$S$ : jumlah genera

\section{Hasil dan Pembahasan}

Hasil penelitian keanekaragaman kupukupu (Lepidopera) di Taman Bunga Merangin Garden terkoleksi 538 individu yang terdiri atas 3 famili yaitu Pieridae, Nymphalidae, dan Papilionidae. Jumlah individu kupu-kupu tertinggi terkoleksi pada penelitian ke III yaitu sebanyak 140 individu (16 spesies) dan yang 
paling sedikit terkoleksi pada penelitian ke IV sebanak 57 individu (14 spesies) (Tabel 1). Penurunan jumlah individu kupu-kupu ini disebabkan oleh banyaknya bunga yang tidak berbunga. Sedgley dan Griffin (1989) menyatakan bahwa ketersediaan pakan berkaitan erat dengan keanekaragaman dan kelimpahan kupu-kupu yang ada, semakin melimpahnya ketersediaan sumber pakan, semakin tinggi jenis kupu-kupu yang datang. Spesies yang mendominasi adalah Junonia orithya $(16,4 \%)$.

Hasil analisis keanekaragaman dengan indeks $\left(\mathrm{H}^{\prime}\right)$ menunjukkan keanekaragaman spesies tertinggi terdapat di penelitian ke III yaitu dengan nilai indeks keanekaragaman 2.62, dan memiliki indeks (D) yaitu 0,08 . Keanekaragaman spesies terendah terdapat pada pengambilan sampel ke VI yaitu dengan nilai indeks keanekaragaman 2.40 dengan memiliki indeks (D) yaitu 0,11 (Tabel 1). Nilai indeks dominansi Simpson (D) digunakan sebagai pembanding terhadap nilai indeks keanekaragaman Shannon (H'). Komunitas dengan nilai indeks dominansi tinggi, maka akan menunjukkan nilai indeks keanekaragaman yang rendah dan sebaliknya (Odum, 1993).

Rentang nilai dari indeks dominansi berkisar antara 0 sampai 1 , dengan kriteria jika nilai indeks dominansinya mendekati 0 maka tidak ada suatu spesies yang mendominasi, tetapi nilai indeksdominansi mendekati 1 maka ada sautu spesies yang mendominasi atau jika hanya ada 1 spesies di dalam suatu komunitas maka nilai dominansinya 1 (Munthe et al., 2012).

Tabel 1. Spesies Kupu-Kupu yang Terkoleksi di Merangin Garden

\begin{tabular}{|c|c|c|c|c|c|c|c|c|}
\hline \multirow{2}{*}{ Taxon } & \multirow{2}{*}{ Spesies } & \multicolumn{5}{|c|}{ Jumlah cacah individu } & \multirow{2}{*}{$\sum$} & \multirow{2}{*}{$\%$} \\
\hline & & $\mathrm{I}$ & II & III & IV & $\mathrm{V}$ & & \\
\hline Lepidotera & 1. Eurema hecabe & 11 & 10 & 13 & 4 & 12 & 50 & 9,3 \\
\hline \multirow{3}{*}{ Pieridae } & 2. Appias libythea & 9 & 13 & 15 & 7 & 14 & 58 & 10,8 \\
\hline & 3. Leptosia nina & 8 & 12 & 14 & 7 & 12 & 53 & 9,9 \\
\hline & 4. Catopsila pyranthe & 16 & 15 & 14 & 8 & 16 & 69 & 12,8 \\
\hline Lepidoptera & 5. Mycalesis sp. & 2 & 2 & 8 & 0 & 6 & 18 & 3,3 \\
\hline \multirow[t]{10}{*}{ Nymphalidae } & 6. Junonia orithya & 14 & 23 & 19 & 11 & 21 & 88 & 16,4 \\
\hline & 7. Junonia hedonia & 6 & 6 & 2 & 4 & 1 & 19 & 3,5 \\
\hline & 8. Hypolimnas bolina & 7 & 5 & 4 & 2 & 5 & 23 & 4,3 \\
\hline & 9. Doleschallia bisaltide & & 3 & 7 & 1 & 4 & 19 & 3,5 \\
\hline & 10. Ideopsis juventa & 1 & 5 & 5 & 4 & 4 & 19 & 3,5 \\
\hline & 11. Elymbias nesaea & 2 & 1 & 4 & 2 & 1 & 10 & 1,9 \\
\hline & 12. Orsotriaena medus & 12 & 5 & 11 & 2 & 6 & 36 & 6,7 \\
\hline & 13. Neptis hylas & 4 & 9 & 9 & 1 & 2 & 25 & 4,6 \\
\hline & 14. Junonia atlites & 6 & 7 & 5 & 2 & 4 & 24 & 4,5 \\
\hline & 15. Elymnias sp. & 0 & 3 & 4 & 2 & 1 & 10 & 1,9 \\
\hline $\begin{array}{l}\text { Lepidoptera } \\
\text { Papilionidae }\end{array}$ & 16. Papilio demoleus & 5 & 1 & 6 & 0 & 5 & 17 & 3,2 \\
\hline Total Individu & & 07 & 120 & 140 & 57 & 114 & 538 & $100 \%$ \\
\hline Total Spesies & & 5 & 16 & 16 & 14 & 16 & & \\
\hline Indeks shannon ( $\left.\mathrm{H}^{\prime}\right)$ & &, 51 & 2,49 & 2,62 & 2,40 & 2,45 & & \\
\hline Indeks simpson (D) & & ,09 & 0,10 & 0,08 & 0,11 & 0,10 & & \\
\hline
\end{tabular}

Ket : I: tanggal 9-15 Desember 2018, II: 23-29 Desember 2018, III: 6-12 Januari 2019, IV: 20-26 Januari 2019, V: 3-9 Februari 2019.

Pada saat semakin tinggi nilai indeks keanekaragaman maka komposisi penyusun komunitas memiliki keanekaragaman spesies yang tinggi dengan kelimpahan individu tiap spesiesnya hampir sama dan jika semakin tinggi nilai indeks dominansi mendekati nilai 1 , maka komposisi penyusun suatu komunitas terdapat satu atau lebih spesies dengan kemelimpahan individu yang sangat tinggi.

Tingginya nilai indeks keanekaragaman pada penelitian ke III disebabkan banyaknya bunga yang bermekaran. Secara umum kupukupu mengunjungi bunga karena adanya faktor penarik yaitu bentuk bunga, warna bunga, 
serbuksari, nektar dan aroma (Apituley et al,, 2012). Bentuk morfologi bunga mempengaruhi jenis serangga pengunjungnya. Menurut Yuliani et al., (2013) menyatakan pada bunga Nerium oleander yang memiliki bentuk bunga seperti kecubung dengan produksi nektar berada pada dasar bunga dengan kedalaman $\pm 25 \mathrm{~mm}$, hal ini menyebabkan jenis serangga polinator yang berkunjung paling banyak dari Ordo Lepidoptera. Kupu-kupu (Lepidoptera) dapat dikatakan sebagai polinator hal ini dikarenakan selain konsumsi nektar juga mengkonsumsi serbuksari serta dapat mentransferkan polen bunga ke bunga yang lain (Banjo et al. 2006).

Kupu-kupu melimpah pada musim bunga dikarenakan tersedianya sumber pakan yang digunakan untuk pertumbuhan dan perkembangbiakan. Hal ini dikarenakan serangga polinator mengunjungi buah apel karena adanya nektar ekstrafloral yang dihasilkan oleh bagian tumbuhan selain bunga. Kandungan nektar sangat dipengaruhi oleh faktor lingkungan terutama kelembaban dan temperatur udara. Hampir seluruh daun, buah, dan bunga dari tumbuhan inang mengandung 30-80 tau lebih komponen senyawa volatil (senyawa yang mudah menguap) yang terdiri dari tipe dan struktur kimia yang sangat beragam. Serangga mampu merespon tumbuhan inangnya karena tingginya sensitivitas pada organ reseptor penciumannya. (Apituley et al., 2012).

Tabel 2. Jenis bunga di taman bunga Merangin Garden

\begin{tabular}{|c|c|c|c|c|c|c|c|}
\hline \multirow{2}{*}{ No. } & \multicolumn{2}{|l|}{ Nama spesies } & \multicolumn{5}{|c|}{ Status bunga pada pengamatan } \\
\hline & Nama ilmiah & Nama lokal & I & II & III & IV & $\mathrm{V}$ \\
\hline 1 & $\begin{array}{l}\text { Apocynaceae : } \\
\text { Catharanthus roseus }\end{array}$ & Bunga tapak dara & $\checkmark$ & $\checkmark$ & $\checkmark$ & - & - \\
\hline 2 & $\begin{array}{l}\text { Allamanda } \\
\text { cathartica }\end{array}$ & $\begin{array}{l}\text { Bunga terompet } \\
\text { emas }\end{array}$ & $\sqrt{ }$ & $\checkmark$ & $\checkmark$ & - & - \\
\hline 3 & $\begin{array}{l}\text { Nictaginaceae } \\
\quad \text { Bougainvillea sp. }\end{array}$ & Bunga kertas & $\checkmark$ & $\checkmark$ & $\checkmark$ & $\checkmark$ & $\checkmark$ \\
\hline 4 & $\begin{array}{l}\text { Asteraceae } \\
\qquad \text { Helianthus annuus }\end{array}$ & Bunga matahari & $\checkmark$ & $\checkmark$ & $\checkmark$ & - & $\checkmark$ \\
\hline 5 & Zinnia elegans & Kembang Kertas & - & $\checkmark$ & $\checkmark$ & - & \\
\hline 6 & Cosmos caudatus & Bunga kenikir & $\checkmark$ & $\checkmark$ & $\checkmark$ & $\checkmark$ & $\checkmark$ \\
\hline 7 & Zinnia peruviana & Kembang Kertas & $\sqrt{ }$ & $\checkmark$ & $\checkmark$ & - & - \\
\hline 8 & $\begin{array}{l}\text { Portulacaceae } \\
\text { Partulaca sp. }\end{array}$ & Bunga krokot & $\sqrt{ }$ & $\checkmark$ & $\checkmark$ & $\checkmark$ & $\checkmark$ \\
\hline 9 & $\begin{array}{l}\text { Amaranthaceae } \\
\text { Celosia plumosa }\end{array}$ & Bunga jeger ayam & $\sqrt{ }$ & $\checkmark$ & $\checkmark$ & - & $\checkmark$ \\
\hline 10 & Gomphrena globosa & $\begin{array}{l}\text { Bunga kancing } \\
\text { baju }\end{array}$ & $\checkmark$ & $\checkmark$ & $\checkmark$ & - & $\checkmark$ \\
\hline 11 & $\begin{array}{l}\text { Verbenaceae } \\
\text { Lantana camara }\end{array}$ & Bunga tahi ayam & $\checkmark$ & $\checkmark$ & $\checkmark$ & $\checkmark$ & - \\
\hline 12 & $\begin{array}{l}\text { Rubiaceae } \\
\text { Ixora sp. }\end{array}$ & Bunga soka & $\checkmark$ & $\checkmark$ & $\checkmark$ & $\checkmark$ & - \\
\hline 13 & $\begin{array}{l}\text { Oleaceae } \\
\text { Jasminum sambac }\end{array}$ & Bunga melati & $\checkmark$ & $\checkmark$ & $\checkmark$ & - & $\checkmark$ \\
\hline 14 & $\begin{array}{l}\text { Turneraceae } \\
\text { Turnera subulta }\end{array}$ & $\begin{array}{l}\text { Bunga } \quad \text { Pukul } \\
\text { Delapam }\end{array}$ & $\checkmark$ & $\checkmark$ & $\checkmark$ & - & $\checkmark$ \\
\hline 15 & $\begin{array}{l}\text { Lamiaceae } \\
\quad \text { Plectranthus } \\
\text { scutellarioides }\end{array}$ & $\begin{array}{l}\text { Bunga } \\
\text { Merah }\end{array}$ & - & $\checkmark$ & $\checkmark$ & $\checkmark$ & $\checkmark$ \\
\hline 16 & $\begin{array}{l}\text { Cannaceae } \\
\text { Canna indica }\end{array}$ & Bunga Tasbih & $\checkmark$ & $\checkmark$ & $\checkmark$ & - & $\checkmark$ \\
\hline
\end{tabular}

Keterangan $:(\checkmark)=$ bunga mekar; $(-)=$ bunga tidak mekar 
Kupu-kupu mengumpulkan nektar dari kelenjar nektar floral (gambar 1) dan ekstrafloral dari berbagai bunga. Nektar floral adalah kelenjar nektar yang terdapat pada bunga sedangkan nektar ekstrafloral adalah nektar yang berasal dari bagian lain selain bunga (kuncup daun, ujung batang) (Marazzi at al, 2013). Nektar dari nektar floral mengandung sukrosa, glukosa, fruktosa, sedikit asam amino, dan lemak (Garcia dan Gottsberger, 2009).

Berdasarkan hasil peneltian, jenis tanaman berbunga Merangin Garden ditemukannya sebanyak 16 spesies dari 11 famili yang secara keseluruhan didominasi oleh famili Asteraceae (Tabel 1). Famili Asteraceae merupakan salah satu famili tumbuhan yang disenangi oleh kupu-kupu kelompok famili Nymphalidae (Alfida dkk, 2016), hal ini dikarenakan famili asteraceae memilki sumber nektar bagi kupu-kupu.

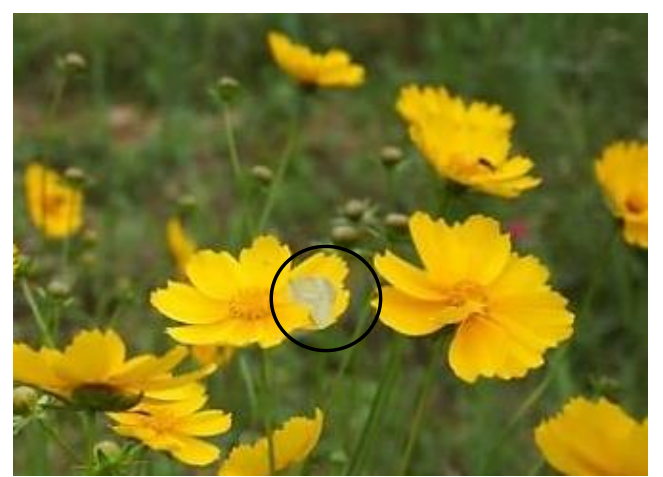

Gambar 1. Kupu-kupu mengunjungi bunga untuk mencari nektar

Sumber : Dokumentasi Pribadi, 2019
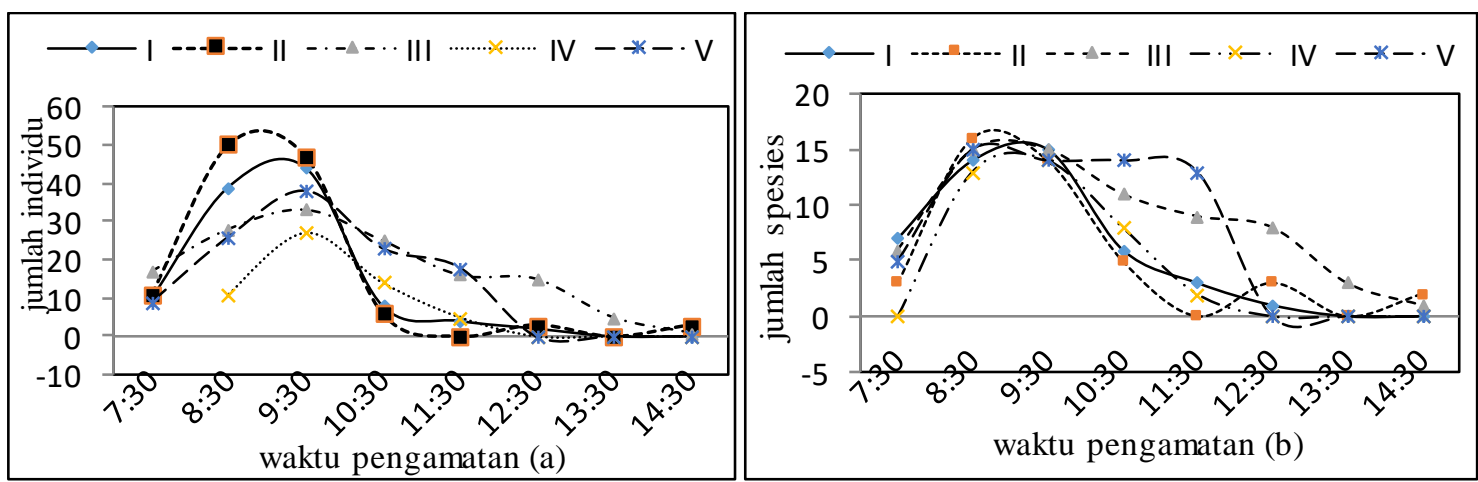

Gambar 2. Jumlah individu kupu-kupu (a) dan jumlah spesies kupu-kupu (b) yang ditemukan di taman bunga merangin garden pada waktu pengamatan yang berbeda (Desember-Maret) 
Kelimpahan spesies kupu-kupu meningkat jumlahnya dari jam 07.30 WIB hingga jam 09.30 WIB dan selanjutnya menurun (Gambar 2b). Penurunan jumlah spesies ini terjadi seiringan dengan penurunan jumalh individu masing-masing spesies (gambar 2a). Jumlah individu kupu-kupu teramati tertinggi terjadi jam 08.30 hingga 09.30 WIB (Gambar 2a). Peningkatan kemelimpahan ini terkait dengan ketersediaan sumber pakan yang disediakan oleh bunga dan sedikit gangguan (faktor abiotik).

Menurut Schlindwein et al (2014), bunga mulai mekar pukul 06.00-17.00 WIB. Ketika bunga mulai mekar, sebagian besar stigma masih tertutup, sedangkan kepala sari sudah turun dan menghasilkan serbuk sari yang juga penarik serangga polinator, 15 menit setelah pembukaan bunga, lobus stigma mulai terbuka dan berlanjut sampai permukaannya mencapai pembukaan maksimal (30 menit), dengan $45^{\circ}$ diantara lobus, ketika bunga mekar, nektar mulai diproduksi sebagai sumber pakan bagi serangga polinator. Peningkatan jumlah spesies dan kelimpahan individu pada pagi hari disebabkan ketersediaan sumber nektar. Volume nektar bunga paling tinggi pada pagi hari (pukul 09.00) dan akan menurun hingga sore hari hal ini disebabkan oleh semakin lama paparan intensitas matahari menyebabkan penguapan nektar (Yuliani et al., 2013).

\section{Kesimpulan}

Kupu-kupu yang terkoleksi sebanyak 538 individu dengan jumlah spesies sebanyak 16 spesies. Keanekaragaman kupu-kupu tertinggi pada penelitian ke III dengan nilai indeks shannon wiener 2,65 dan Simpson 0,08. Hal ini juga didukung oleh keadaan sumber makanan yang melimpah dengan banyaknya bunga yang mekar saat penelitian ke III. Jenis bunga yang bermekaran yang menyebabkan perbedaan stabilitas kehadiran kupu-kupu di habitat ekowisata taman bunga merangin garden.

\section{Referensi}

Alfida., Hanum,U., \& Eliyanti. (2016). Kupu-Kupu (Rhopalocera) di Kawasan Hutan Kota BNI Banda Aceh, Jurnal Biotik, Vol. 4, No. 2, Hal. 117-127.

Apituley, F.L., Leksono, A.S., dan Yanuwiadi, B. 2012. Kajian Komposisi Serangga Polinator Tanaman Apel (Malus Sylvestris Mill) di Desa Poncokusumo Kabupaten Malang. Kajian
Komposisi Serangga. Vol. 2, No.2 Maret 2012. (85-96)

Borror, D.J., Triplehorn,C.A., \& Jonhson, N.F. (Ed) (1992). Pengenalan pelajaran serangga. Yogyakarta: Gajah Mada University Press.

Brewer, R. (1994). The Science of Ecology. McGraw-Hill Company.

Fiedler, A.K., Landis, D.A., Wratten, S.D. 2008. Maximizing ecosystem services from conservation biological control: The role of habitat management. Biological Control 45 (2008) 254-271

Fox, R., Harrower, C. A., Bell, J. R., Shortall, C. R., Middlebrook,I., \& Wilson, R. J. (2018). Insect population trends and the IUCN Red List process. Journal of Insect Conservation.https://doi.org/10.1007/s108 41-018-0117-1.

Galetto, L., \& Torres, C., (2002). Are Nectar Sugar Composition and Corolla Tube Length Related to the Diversity of Insects that Visit Asteraceae Flowers. Plant biology (Stuttg); 4(3): 360-366. DOI: 10.1055/s-2002-32326

Gandi, S., \& Kumar, D., (2015). Studies on Butterfly diversity, abundance and utilization of plant resources in urban localities of Banyan city-Vadodara, Gujarat, India. Journal of Entomology and Zoology Studies. Vol 3(4): 476-480.

Garcia, M.T.A., \& Gottsberger, G. (2009). Composition of the floral nectar of different subgenera of Argentinian passiflora species. Plant Syst Evol. Vol. 283:133-147.

Ghazanfar, M., Malik, M. F., Hussain, M., Iqbal, R., \& Younas, M. (2016). Butterflies and their contribution in ecosystem: A review. Journal of Entomology and Zoology Studie. Vol. 4(2): 115-118.

Gullan, P.J., \& Cranston, P.S.(2010). The insect: an Outline of Entomology. United Kingdom: Wiley-Blackwell.

Koneri, R \& Maabuat, P.V. (2016). Diversity of Butterflies (Lepidoptera) in ManemboNembo Wildlife Reserve, North Sulawesi, Indonesia. Pakistan Journal of Biological Sciences. Vol. 19 (5):202-210.

Leo, S., Avifah, N., Sasangka, A.N., \& Zahra, S. (2016). Butterflies of Baluran National Park, 
East Java, Indonesia. Pros Sem Nas Masy Biodiv Indon. Volume 2, Nomor 2

Marazzi, B., Bronstein, J.L., \& Koptur, S. (2013). The diversity, ecology and evolution of extrafloral nectaries: current perspectives and future challenges. Annals of Botany. Vol.111: 1243-1250.

Odum, E. (1993). Dasar-dasar Ekologi. Yogyakarta: Gadjah Mada University press.

Peggie, D. \& Amir, M. (2006). Panduan Praktis Kupu-kupu di Kebun Raya Bogor. Puslitbang Biologi. Bogor: LIPI Press.

Schlindwein, C., Westerkamp, C., Carvalho, A.T., \& Milet-Pinheiro,P. (2014). Visual signalling of nectar-offering flowers and specific morphological traits favour robust bee pollinators in the mass-flowering tree Handroanthus impetiginosus (Bignoniaceae). Botanical Journal of the Linnean Society. 176, 396-407.

Sedgley, M dan Griffin, A.R. 1989. Sexual Reproduction of Tree Crops. Forest Ecology and Management. Volume 35,

Tiple, A.D. (2012). Butterfly species diversity, relative abundance and status in Tropical Forest Research Institute, Jabalpur, Madhya Pradesh, central India. Journal of Threatened Taxa. Vol. 4(7): 2713-2717.

Yanuar, A., Mun'im, A., Lagho, A.B.A., Syahdi, R.R., Rahmat, M., \& Suhartanto, H. (2011). Medicinal Plants Database and Three Dimensional Structure of the Chemical Compounds from Medicinal Plants in Indonesia. International Journal of Computer Science Issues, Vol. 8,

Zhongmin, W., dan Yunfei, Y. 2012. Species diversity of butterflies in Changbai Mountain in China. Acta Ecologica Sinica 32 (2012) 279-284 